\title{
The Monetary Policy of Central Bank of Albania: Undertaken Contrasting Measures Against Global Crisis
}

\author{
Doris Madhi \\ PhD Candidate, Faculty of Economy University of Elbasan, Albania \\ Email: dorismadhi@gmail.com
}

\section{Doi:10.5901/ajis.2015.v4n2s2p218}

\section{Abstract}

\begin{abstract}
Important data regarding the growth rate and the macroeconomic balance preservation show that Albania has experienced an important challenge the last 5 years. The effects of the global crisis are indirectly spread into the Albanian economy, considering the fact that the most important commercial partners to Albania are Italy and Greece, two countries of Eurozone in serious financial and internal debt crisis. The spread of the financial crisis from USA to Europe has made it difficult to find credit in the market, which leads to incremental liquidity and credit risk, associated to interest rate increases, increased difficulties encountered by the private investors, lower consume and a high grade of economic uncertainty. Also, the prices of some important primary products such as petroleum are still located in high levels. What mentioned above, in Albania was translated into lower remittances (as almost 1/3 of the Albanian population emigrates in Italy and Greece). On the other part, the partner's private sector difficulties to produce incomes have played an important negative role on the Albanian exports amount, causing a commercial deficit. Consume and private investments are also decreased. In order to contrast the crisis effect the Albanian government has grown its debt. This work will treat about the measures taken by the Albanian Central Bank, in order to avoid the foreign imported financial difficulties and risk and in order to stimulate growth, private investments and consume. The traditional and not traditional monetary policy tools and instruments will be analyzed, with special acuity towards all the macroeconomic indicators and the related effects. This paper aims to verify the effectiveness of the monetary policy in Albania through an accurate analysis, supported by empirical data in a range of five years.
\end{abstract}

Keywords: Central Bank of Albania, financial crisis, macroeconomic indicators, monetary policy, fiscal policy.

\section{The Financial Crisis and Global Imbalances}

The bases of the economic crisis were found to the difficult internal economic situation of the affected countries and to the difficult economic situation of the most powerful countries such as USA, the petroleum biggest exporters, the emergent countries.

Obviously, the globalization has negatively contributed to the asymmetric shocks diffusion on world scale.

The realization of the American dream of the subprime, a pure speculation used by the politicians in order to gain electorate, had a big cost, supported by the global economic system, which was feeding with international incomes the American loans. the world.

The term global imbalances mean persistent imbalances to the international payments system in several areas of

There are different reasons lying to this:

1. The persistent deficit (by 1982) of the payment balance and the excessive debt in the USA

2. The surplus of the biggest petroleum exporters in the Middle East

3. The lack of dynamicity in the internal EMU demand

4. The elevated savings, the slow consume wages and public expending growth in the emergent countries.

The financial crisis had its origins in the internal imbalances of the most powerful countries.

The effects of the global crisis are indirectly spread into the Albanian economy, considering the fact that the most important commercial partners to Albania are Italy and Greece, two countries of Euro zone in serious financial and internal debt crisis. On the other side, this spread was due to the difficulty to find liquidity and credit in the international market.

During 2009, the effects of the crisis were felt by the Albanian economy, which was strongly supported by the emigrants' remittances. During these years, due to a balanced internal economy, Albania also had an elevated economic growth in comparison to other Balkans and European countries. 
During 2011- on going the crisis effects were more visible, the government increased its debt and several contrasting measures were taken by the Central Albanian Bank also.

\section{The Monetary Policy of the Albanian Central Bank}

The principal objective of the Central Bank of Albania is to maintain and preserve the stability of the prices through an inflation targeting policy. Translated in numbers the aimed inflation growth rate during an annual period has not to exceed a $3 \%$ rate.

Also, the Central Bank, as the responsible designer institution of the monetary policy, has the obligation to maintain its independence in front of any other interested institution. Practically, the monetary policy is based in those main pillars:

- The monetary policy guaranties the prices stability over a medium term in the Albanian economy.

- The monetary policy is future oriented, as its effects take time to be visible because of the financial and real markets fluctuations. Respecting this principle, the monetary policy becomes more effective.

- The monetary policy is balanced. This principle aims to balance the inflation targeting objective with the contrast of the economic fluctuations, helping to maintain a proportional rate of wellness.

- The monetary policy is prudential, which is translated in proper supposes and models in order to contrast uncertainty.

- The monetary policy is guided by transparency principles, maintaining informed the public about the decision making process.

- The monetary policy operates in a fluctuating rate of foreign exchange regime. The maintained foreign currency reserves have to support at least 4 months of imported products in case of necessity and to pay back the foreign short term debt. In order to maintain a high level of reserves, sometimes the Central Bank operates in the internal financial markets. These operations are not part of the monetary policy and do not aim to influence the market.

The operational objective of the Central bank of Albania is to maintain a reduced gap between the interbank interest rates and the basis interest rate over a short term. The orientation of the interest rates and the maintenance of the prices stability play an important role in the economic agents decision making in consume, savings and investments.

The operational instruments of the Albanian Central Bank are:

- Open Market Operations (REPO and Reverse REPO) which aim to influence the short term interest rate and to control the market liquidity.

- Permanent Facilities (1 day loan and 1 day deposit) aim to influence the short term interest rate and to control the market liquidity. Implemented by commercial banks initiative.

- The Mandatory Reserve aims to regulate the money supply, the liquidity state and to manage the interbank interest rate.

- Other instruments, which are used to make more efficient and effective the monetary policy, when other instruments fail or do not operate properly. Ex. The communication of the future monetary policy guides in order to lower the public uncertainty.

\section{The Albanian Central Bank Monetary Policy 2011-2015}

During 2011, the Albanian economy had experienced a moderate rate of growth, considered the uncertain and difficult foreign environment, especially the financial market imbalance.

The economic growth was influenced by the lack of consume and investments. Also, the foreign markets fluctuations had increased the agent's uncertainty, expressing a grown prime at risk in the internal and external market. The petroleum increased price had a negative influence in the Albanian import cost, translated in a high inflation pressure. In this context, the fiscal policy, designed by the Albanian government, was unable to exercise its objective, because of the debt increase.

In order to maintain an economic stability and also to achieve its objectives, the Albanian Central Bank had operated through a prudential policy, having as a primary purpose the Albanian product and service competition growth towards the foreign markets.

During the $3^{\text {rd }}$ trimester of 2011 , the inflation rate was equal to $3.2 \%$, signing a decrease of $0.9 \%$ towards the registered inflation in the $1^{\text {st }}$ trimester. The decrease happened thanks to the food products prices decline in the foreign markets and the increased home production of the imported products. 
The inflation rate during the $3^{\text {rd }}$ trimester of 2011 , was also influenced by the foreign supply pressure, translated in higher commodities prices level, especially petroleum and its derivatives. The well informed economic agents have balanced this pressure through a decreased aggregate demand. The Albanian economy was operating under its effective potential. The consumer and investment indicators remained at low levels, signing a low perspective for the future also. A moderate support to the economy was given by the foreign demand for investments in the industry field.

The public sector had a low contribution in the economic growth during 2011, because of the grown rate of debt (30.7 milliards Lek) and the lower levels of fiscal incomes and government spending.

A positive contribution to the economic growth was given by the foreign demand for home product, causing a decrease of the commercial deficit, presented in a moderate rate $(0.8 \%)$. Structured reformation and higher competitiveness of home products was needed to help decreasing the current balance deficit.

The monetary indicators showed a moderate increased (as expected) inflationary pressure and also a 10.6\% increased monetary supply. The private and individual monetary demand was moderately increased and also the credit loans for these sectors, accommodating the demand.

The credit sector became more prudential towards privates and individuals asking for loans, because of the increased uncertainty in the financial markets and the decreased orientation for investments, but was also trying to keep a low interest rate.

The credit sector was liquid and solid enough, supported by increased commercial volume in the interbank market under low interest rates.

Given this situation, the Central Bank has decreased the official interest rate by $0.25 \%$ during 2011 , in order to help and incentive the aggregate demand growth and to preserve the prices stability.

During 2012, the operating Albanian environment was experiencing a national and foreign supply shock, which influenced the economic growth, lowering its level. The foreign demand was reduced and the prime at risk was increased, reflected in a decline of consume and investments.

Also, the fiscal stimulation was lower than a year ago, exercising a negative pressure on the aggregate demand.

The Central Bank of Albania was able to fulfill its primary objective, helped also by the good performance of the real estate and financial home markets. The average registered inflation rate during 2012 was $2.7 \%$. The contained inflation was due to minimal home and imported consume products prices and also to a balanced rate of exchange.

The Albanian economic growth was $2 \%$, sustained by the growth in agriculture, industry and services sectors. A decline was registered in the construction sector.

By the aggregate demand point of view, the economic growth primarily was sustained by the foreign demand. The home demand remains lower, because of the uncertainty, the lack of dynamism in the wages sector and the decline of the personal incomes after taxes. The private investments also remain in a low level, because of the difficulty to find credit, the lack of demand for their final products and the lack of fully exploited resources. The investment decrease caused a decrease in the real estate sector also.

The commercial deficit decreased by $5.4 \%$ during 2012 , thanks to the incremented exports by $6.7 \%$ and the decremented imports by $0.9 \%$. Also, the sensible decrement of the current balance deficit, gave a positive signal over the demand-supply equilibrium for foreign currencies in the home market.

The monetary sector confirms the low inflationist pressure over the economy, because of a low internal demand for money. The credit towards the private sector is at a $5 \%$ level, following the slowing trajectory of 2011 . The banking sector basis its operations in home currency intermediation, more than in foreign currencies, showing interest in home currency investment, given the foreign values uncertainty.

The weaker demand for money had caused the low demand in the banking sector. The money supply was also low, as bankers became prudential in the credit risk evaluation, given the quality decline of the client portfolio.

The Central Bank considered that the banking sector was well capitalized and sufficiently liquid to support the private sector investments and the economy.

The financial markets were characterized by a declining trend of the offered yield, reflecting the monetary policy facilitating role.

The decline of the offered yields on government bonds reflects a lower need for financing and also an efficient monetary policy.

The deposits amounts were incremented and the related interest rate decremented. The facilitation of the financing cost decrement found difficulty in its transmission in the private sector credit accord, because of the high intermediation costs applied by the commercial banks.

In order to facilitate the economic growth and prices stability, the Central Bank applied a further interest rate 
decrement equal to $0.25 \%$. The interest rate arrived at his historical minimum of $4 \%$. Also, the Central Bank continued the liquidity injections through its operations, in order to fulfill the monetary demand.

During 2013, the Albanian economy was characterized by a slow economic growth of 1.1\%, which finds its reasons in a weak private demand for consume and investments, even though the fiscal policy facilitations were operating. Also, the foreign demand was weak because of the Albanian commercial partners' experienced economic difficulties.

The incremental uncertainty of the markets pushed the economic agents to lower their investments demand and also the credit sector to restrict the private and individual financing. The conservative behavior of the credit sector stopped the transmission effects of the monetary policy.

Even though, the Central Bank considers that the economic and prices stability were preserved and followed the provisional line, helping the economic agents expectations and activities. Also, the banking sector was healthy, even the incremented bad creditors.

The inflation rate follows a declining line at about 1.5\%, thanks to the home agricultural products low price contribution, that fulfilled almost completely the intern demand. Also, the prices of the imported refined products were decreased.

The persistent low inflation was an indicator of a negative production gap. The internal demand weakness had created unexploited resources and a lack of pressure increment in the wages and product prices.

Also, the real estate market trend shows a weak demand, preserving a low inflation rate, helped by a low monetary expansion.

The economic growth was supported by the public sector demand, as the private and individual sector demand was very low in terms of consume and investments, because of the markets uncertainty and the financing sources difficulties.

The fiscal policy was representative of facilitating and stimulating measures, reflected in the fiscal indicators as follows: the government expenditures were incremented on a rate of $8.3 \%$ in current and capital terms; the fiscal incomes were decremented by $4 \%$, because of the related factors decrease. The trend of the government incomes and expenditures has created a budget deficit increase of $1.25 \%$, financed by internal long term instruments.

The foreign commercial part of the demand was weak, reflected in a negative contribution on the aggregate demand. The net real exports were reduced and the imports incremented. The commercial deficit was reduced by $15 \%$, thanks to the exports increase by $15.1 \%$ in products and the import decrease of $3 \%$.

The financial markets present lower prime at risk. The interbank sector intermediates a larger volume using lower interest rates. In the primary market, lower yield rate was applied to the high maturity bonds. Also, decreasing interest rates were applied to the deposits and loans. The private and individual demand of financing and loans remains weak.

A positive development was signed by the bad creditor's clearance in the banking statements, thank to an efficient implemented process.

In a long term, the expected effects are very positive and will incentive the healthy financing process.

The monetary supply side also shows a decline of $2.7 \%$, because of the low level of foreign values in entrance and the low level of financing demand by privates and individuals. By the other side, the increased financing of the public sector supports the monetary increase in the Albanian economy.

During 2014, the data regarding the economic growth show a transitory declining trend, because of the real estate sector declining tendency. The declining economic activity was measured through the added value. Also, the inflation rate was low, because of the not expected supply shocks.

The Central Bank had balanced economic expectations in a medium term, helped by a stimulating monetary policy on consume and investments.

The available data were not very accurate in quality and interpretation, so, the Central Bank had evaluated the difficulty to accomplish its primarily objective (inflation) in a medium term. Further revisions on a facilitating monetary policy had to be implemented.

The inflation rate was at a 1.7\%, due to the low food products and rent prices. The low inflation rate reflects the not fully exploited resources in the economy, which create a negative pressure in the labor and production costs. At the same time, the inflation rate was influenced by the low inflation rate in the commercial partner's countries, by the low inflations expectations and the low pressure of liquidity in the economy.

The Central Bank's expectations in a medium term, regarding inflation and the growth rate were optimist and valuated to converge versus the equilibrium.

The consume and investments trend remains positive, even the diminished added value of $0.6 \%$, because of a declining operability in the transports, constructions and industry sectors. On the other part, the services sector 
experienced a high added value.

The aggregate demand restriction was due to a restricted fiscal stimulation and to the negative net exports contribution. The positive gap between exports and imports was created because of the demand-supply relation in absence of fluctuations on the currency rate.

The fiscal consolidation strategy has given stopping impulses to the aggregate demand, because of the reduction of $53.1 \%$ of the budget deficit. This strategy reflects more fiscal incomes and lower government investments. The Central Bank considers that the effects of the monetary policy depend on the fiscal policy achievements regarding the debt consolidation and the fiscal corrections.

The monetary policy was based on a stimulating strategy, lowering by $2.5 \%$ the interest rate. The private loans sector reaction shows a certain growth of $2.5 \%$, but still remains slow. Following the monetary policy objectives of credit stimulations, available data show positive signs regarding to the private sector financing conditions.

During the $1^{\text {st }}$ trimester of 2015 , the economic growth presented an increasing trend and the aggregate demand also, thanks to an increased economic activity and an enforced inflationary pressure. The rate of inflation is equal to $1.9 \%$, because of the food products increased prices over the expectations. As the prices increased due to seasonal supply shocks, the Central Bank considers these effects as temporarily. On the other side, a negative contribution was given by the petroleum price, which was balanced by appreciation of the dollar against our currency, Lek.

In the economy remains still the lack of fully exploited resources, which keeps the economic activity under its potential and the inflation rate under the Central Bank target level.

The annual growth of the added value is equal to $1.9 \%$, thanks to the incremented productions in agricultural and services sectors. The economic growth reflects the internal private demand positive trend and the positive contribution of the government spending. On the other side, the foreign demand is weak and its contribution to the economic growth is not positive.

The interest rate is reflecting a further decrease of $2 \%$, in order to stimulate the aggregate demand, to lower the financing costs and to return to inflation targeting policy. However, the facilitating interest rates find difficult its transmission in the credit sector increase, because of the banker's conservatory behaviors and the decreased demand for loans.

\section{Conclusions}

During the last 5 years the Albanian economy has encountered a series of difficulties due to the asymmetric demand and supply shocks imported by the foreign financial markets. Also, the intern environment was characterized by a low demand for consume and investments and a high public debt. As the fiscal policy effects were mostly negative, because of the low public spending and the high intern and foreign debt, even the undertaken measures in debt consolidations, the Central Bank of Albania played a central role related to the accomplishment of its objectives and the markets stability preservation in the economy.

As mentioned above, the principal objective of the Albanian Central Bank is the maintenance of the inflation rate in a maximum level of 3\%. During 2011-2015, the inflation rate has followed a decreasing line, because of the decreasing commodities and food product prices (mostly imported). Also, the persistent low inflation has reflected its effects in the home labor and production costs, causing a lack of dynamism. The decreasing operational tendency in the real estate markets has contributed to maintain a low inflation rate. Even the economic growth was moderate in comparison with other European countries its rhythm was slow, because of the decrease in consume and investments. This decrease was due to the lower remittances, the increased uncertainty in the financial markets and the low monetary expansion. During these years the banking sector was solid, liquid and healthy enough to finance the private and individuals, but a conservatory and prudential behavior was chosen. The Central Bank's monetary policy aimed to stimulate crediting and financing in the Albanian economy, lowering continuously the bases interest rates and the bond yields rate. Also, the prime at risk was low and the interest rates in loans and deposits too. The clearance process of bad creditors and the increased certainty in the banking sector, gave positive signs related to its development.

Also, the Central Bank, in order to facilitate the financing process of the private and individual sector has accommodating the aggregate demand through a positive money supply.

Even the positive effects of the monetary policy, the Central Bank considers that the spread of its policy effects depend on the fiscal policy achievements and debt consolidation strategy. Also, it stresses on the opportunities to be created in order to increase the competitiveness of the home products, in order to stimulate the wages sector, to increase consume and investments and to decrease the commercial deficit balance. 
Concluding, during these years the Albanian Central Bank has done a great job, even the markets fluctuations, sustaining the economy growth and aiming to stimulate consume and investment through a facilitating monetary policy, but more accurate provisional models are acquired and a conjunctive implemented monetary and fiscal policy too.

\section{Reference}

Acocella N., "Le istituzioni pubbliche su base regionale:l'Unione Europea", in "La politica economica nell'era della globalizzazione", Seconda edizione, Carocci Editore, 2005, pg.152.

Targetti F., Tamborini R., "Globalizzazione, squilibri e crisi", in Barucci E., Messori M., (a cura di), "Oltre lo shock. Quale stabilita per $i$ mercati finanziarr", Egea, 2009, pg.4-8

Bank of Albania, "Monetary Policy Report 2011"

Bank of Albania, "Monetary Policy Report 2012"

Bank of Albania, "Monetary Policy Report 2013"

Bank of Albania, "Monetary Policy Report 2014"

Bank of Albania, "Monetary Policy First Trimester Report 2015" 